\title{
Assessment of lactation curve parameters for test-day Milk yield, Fat $\%$ and SNF\% in Murrah Buffalo
}

\author{
Uma Kant Verma, Vikas Vohra, ID Gupta, A Verma, A Mukherjee and SM Deb
}

Received: 18 October 2019 / Accepted: 28 October 2019 / Published online: 31 December 2019

(C) Indian Dairy Association (India) 2019

\begin{abstract}
A lactation curve can reveal abundant information about the pattern and persistency of lactation in an individual dairy animal. Identifying buffalo with particular pattern and persistency of lactation milk yield can serve as additional selection criterion for a dairy herd. Wood's incomplete gamma function fitted well to the monthly test-day milk, fat $\%$ and SNF\% yields of Murrah buffaloes and can be used in prediction of milk and milk constituents yield with higher accuracy. We also report that exponential function (Wilminks model) also can be used in prediction of milk constituents in Murrah buffaloes when constant $\mathrm{k}$ is changed in the model from 0.05 to 0.06 or 0.07 . Thus, these functions can be used to make breeding and management related decisions particularly selection of desired and persistent buffaloes and thus improving the production of the herd by culling non-desired type of Murrah buffaloes.
\end{abstract}

Keywords: Buffalo, Fat, Lactation Curve, Milk, Murrah, SNF, Wood's, Wilmink

\section{Introduction}

Buffalo is a multi-utility species, and Murrah breed of buffalo is primarily reared for milch purpose in India. Present buffalo population in India is 109.85 million and has shown a growth of

Animal Genetics and Breeding Division, ICAR-National Dairy Research Institute, Karnal 132001, Haryana, India

Vikas Vohra $(\bowtie)$

Animal Genetics and Breeding Division, ICAR-National Dairy Research Institute, Karnal 132001, Haryana, India

Email: vohravikas@gmail.com
$1.0 \%$ during last five years $\left(20^{\text {th }}\right.$ Livestock Census). Buffalo contributes to annually about 90 million metric ton of milk, which come to around $49 \%$ of the total milk produced, in India. The goal of an animal geneticist is to select and multiply the superior producing buffaloes. Lactation curve parameters and their corresponding shapes can be effectively be used to select the high producing buffaloes. A dairy bovine with a stable or standard lactation curve (non-linear) are considered to be more persistent, compared to those animals who are having steep or skewed lactation curves. Recently, lactation curves are being used for genetic evaluations (Strucken et al. 2011; Jamuna, 2015; Sahoo et al. 2018) as the peak yield and days to attain peak yield in combination with shape of lactation curve can help us in deciding superior dairy animals, as area under a curve represents the yield. Lactation persistency is an another important dairy trait and is defined as the ability of a dairy bovine to maintain its milk at a higher level after she has attained the peak production during the lactation, in other words, if the rate of decline in yield is slow for a dairy animal, such an animal is considered to be a persistent producer. According to Kellogg (1977), lactation curve models serves as a concise summary of the pattern of milk yield determined by the biological efficiency of the dairy animal. Shape of lactation curve and its parameters have also been employed in taking management related decisions, namely, health monitoring and individual feeding etc.

Several parametric models, such as exponential decline function, inverse polynomial function, gamma type function, exponential function, Legendre polynomial function, and mixed log function have been developed to describe the lactation curve in dairy animals (Woods, 1967; Wilminks, 1987; Ali and Schaeffer, 1987; Kirkpatrick et al. 1990; Beever et al. 1991; Sherchand et al. 1995; Grossman and Koops, 1999; Macciotta et al. 2005; Vohra, 2010; Macciotta et al. 2011; Vohra et al. 2011; Prakash et al. 2015; Jamuna 2015, Vohra et al. 2017; Sahoo et al. 2018), differing mainly in the type of regression, in the number of parameters and in their degree of relationships with the main features of a typical lactation pattern, such as peak yield, days to attain peak yield, days in milk and persistency. The shape of lactation curve depicted by individual dairy animal is subjected to random variation and different functions vary in their goodness of fit to individual lactations in different species. Incomplete gamma function and 
exponential function have been most successfully used to depict the shape of lactation curves in cattle but limited work has been carried out in buffaloes. Woods incomplete gamma model (Wood, 1969) and Wilmink's exponential model (Wilmink, 1987) both are three parameter based function namely, initial milk yield (a), rate of incline to attain peak yield (b), and rate of decline after attaining the peak (c). Vohra (2010) studied the mathematical properties of these functions (Woods and Wilmink) and lactation patterns in crossbred cattle (Karan Fries) and advocated that types of lactation curve should be taken in account with the existing expected producing ability based criteria of selection in crossbred cattle for higher milk production.

A better understanding of the mathematical functions is needed among buffaloes for having a better fit model for monthly testday milk and its constituent's traits, also there is a need to identify persistent lactating Murrah buffaloes. Keeping the above in mind, the present work is an attempt to explore the best-fit lactation curve function using monthly test-day milk yield, fat\% and SNF\% in buffalo species. Thus, it becomes important to assess the lactation curve parameters with high accuracy using milk and its constituent traits in Murrah buffalo, so as to identify the superior and persistent buffaloes and to make necessary breeding related decisions.

\section{Materials and Methods}

Study was carried out with 5817 monthly test-day records belonging to 202 calving in Murrah buffalo maintained at livestock farm of National Dairy Research Institute, Karnal (Haryana). The first TD on which milk yield, fat $\%$ and SNF\% records were collected being the $5^{\text {th }}$ day of lactation and $10^{\text {th }} \mathrm{TD}$ being the $275^{\text {th }}$ day of lactation. Buffaloes with only normal lactation were considered in the study and the production data was standardized before analysis (model not presented). The adjusted data was used for fitting the incomplete gamma function, exponential function and Legendre polynomial function.

\section{Incomplete gamma function}

The function was proposed by Woods and the model is known by his name, the function is a three parameter based, Wood (1967). The model had the advantage of having a limited number of parameters with an assessed direct reference to main features of lactation curve, Rekaya et al. (2000).

Wood's Model $\quad . . . . Y \mathrm{Yt}=\mathrm{at}$ b e $\mathrm{e}^{-\mathrm{ct}}$

(Model 1)

Log Linear form of Wood's Model .. $\log Y t=\log a+b \log t+c t$ (Model 2)

Where, $\mathrm{Y}_{\mathrm{t}}=$ fortnightly adjusted test day milk yield at day $\mathbf{t}$ from parturition, $\mathbf{a}=$ initial milk yield, $\mathbf{b}=$ ascending phase of lactation, $\mathbf{c}=$ descending phase of lactation, $\mathbf{t}=$ days in milk.

\section{Exponential function}

The function is also called as Wilmink model (Wilmink, 1987) and like Wood's model it is also a three parameters based function.

Wilmink's Model $\mathrm{Y}_{\mathrm{t}}=\mathrm{a}+\mathrm{b} \mathrm{e}^{-\mathrm{kt}}+\mathrm{ct}$

(Model 3)

Where, $\mathrm{Y}_{\mathrm{t}}$ is test day milk yield at day $\mathrm{t}$ from parturition, $\mathrm{a}$ is initial milk yield, b is ascending phase of lactation, $\mathrm{c}$ is descending phase of lactation, $\mathrm{k}$ varied from 0.05 and $\mathrm{t}$ is days in milk (DIM)

\section{Different exponential constant values}

The constant of 0.05 has been used by Wilmink in his model and it fitted well for cattle species, in the present studies different constant values, ranging from 0.03 to 0.07 were used to fit the exponential function in buffalo species.

\section{Shape of lactation curve and coefficients of determination $\left(\mathbf{R}^{2}\right)$}

Types of lactation curves with different shapes were depicted by Woods function based on their analytical properties that were developed from first/second derivatives as per Macciotta et al. (2005) for individual cow. In the procedure of fitting the different functions to monthly test-day milk and milk constituent yields of each animal for first lactation, the coefficients of determination was estimated for testing the goodness of fitting the curves.

\section{Results and Discussion}

\section{Data Structure and modelling of lactation curves}

Ten test-day records per buffalo per month were utilized in Murrah buffalo to model the lactation curves, using incomplete gamma and exponential functions. The adjusted to monthly test-day milk and milk constituent yields were utilized for obtaining the function parameters namely, initial milk yield (a), ascending phase (b) and decline phase (c). Based on these estimated parameters, different shapes of lactation curve were depicted with variable frequency in the studied population of Murrah buffalo. The four types of lactation curves were depicted using incomplete gamma function (Wood's model) and exponential function (Wilmink's model). Both these functions revealed the following lactation curve shapes viz., standard, continuously increasing, reverse standard and continuously decreasing types in our population of Murrah buffalo. The modelling of different types lactation curve was made for monthly test-day milk yield and milk constituent traits (fat $\%$ and $\mathrm{SNF} \%$ ) in Murrah buffalo. Since, the number of observations across all the monthly test-days were equal, hence fixed regression was used instead of random regression technique. The average estimated lactation curve parameters for monthly test-day milk and milk constituent traits for their corresponding four type of curves depicted by Wood and Wilmink functions (at different constant values of $\mathrm{k}$ ) are 

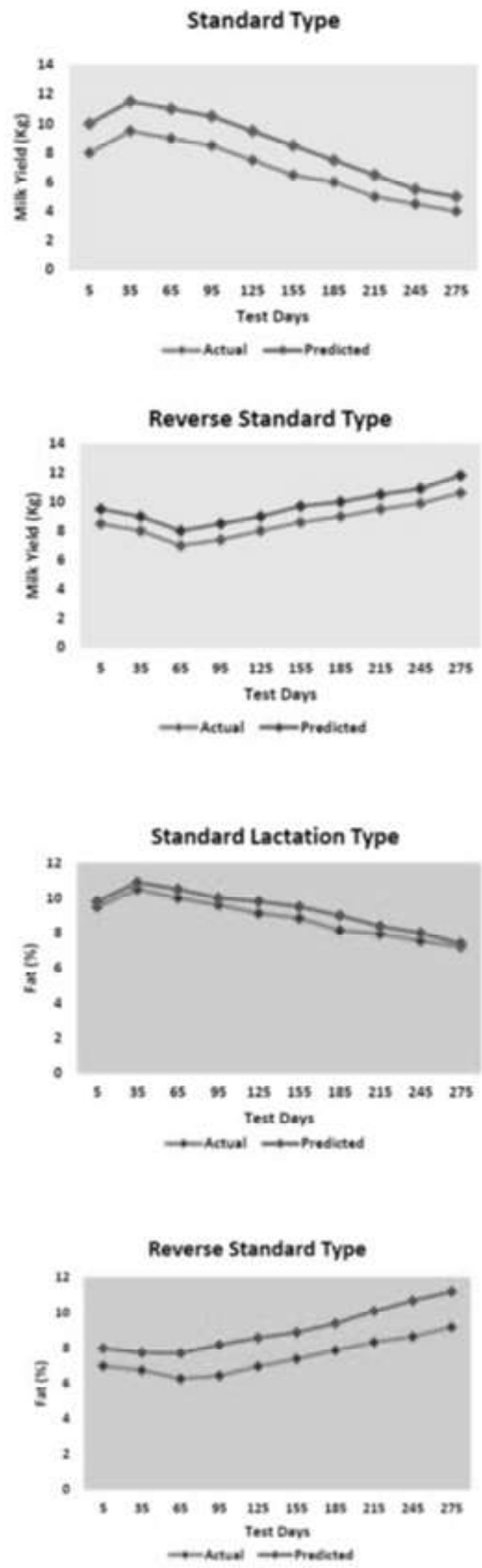
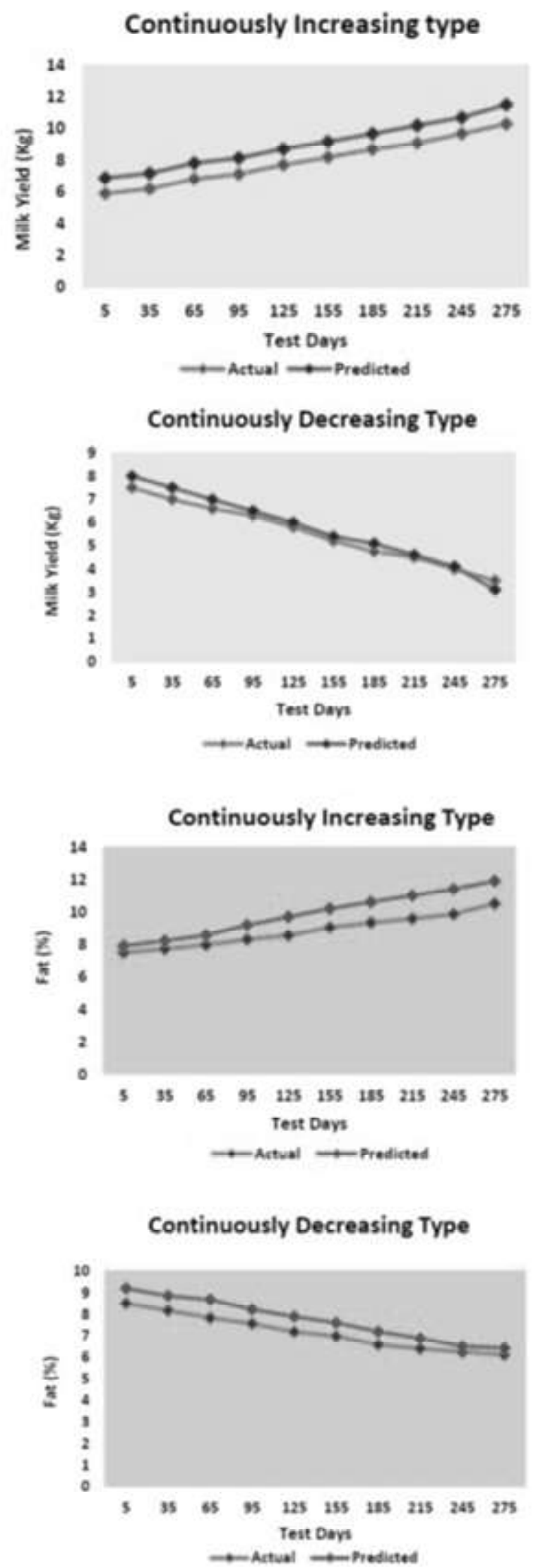

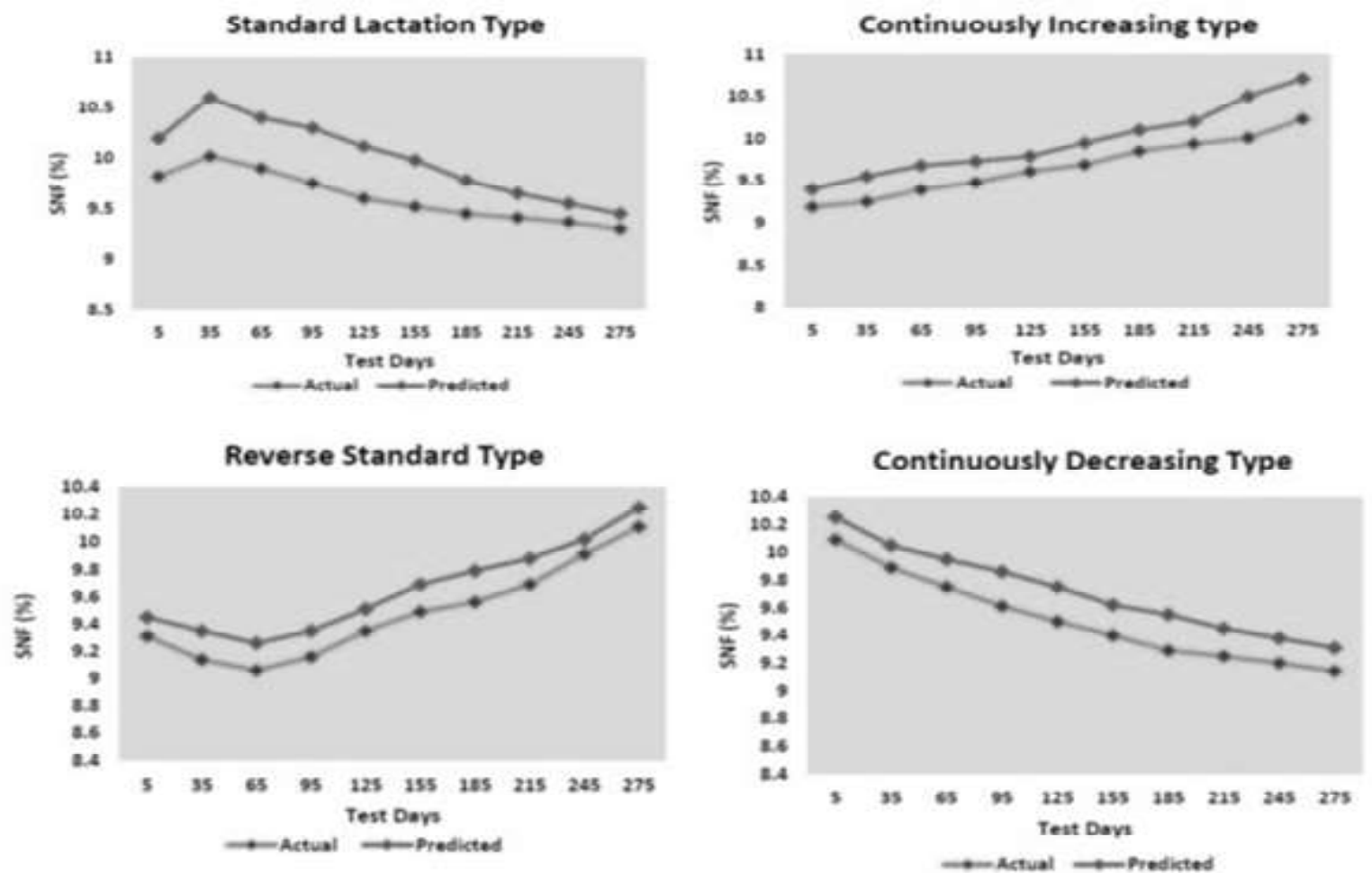

Fig. 1 Different shapes of lactation curves for milk and milk constituents in Murrah buffao

presented in Table 1. Lactation curve was evaluated based on goodness of fit criteria $\left(\mathrm{R}^{2}\right.$ value $)$ and it was found that incomplete gamma function (Woods model) was best fitted function for prediction of monthly test-day milk yield and fat $\%$ and SNF\% (Fig. 1). About 91.08\%, 88.11\% and $92.07 \%$ of Murrah buffaloes depicted desired type of lactation curves and about 8 to 12 percent buffaloes depicted non-desired type of lactation curve for milk yield, fat and SNF percentage, and does not contribute in the farm milk production.

\section{Desired and non-desired type of lactation curves}

In the present study, an attempt has been made to describe the desired/typical and non-desired/atypical forms of lactation curves using Wood and Wilmink functions. The Murrah buffaloes representing either standard curve or continuously increasing type of curve or both are presumed to be better producer for milk and milk constituents and are desired for longer times in a herd, than those depicting either reverse standard type or continuously decreasing type of curve or both. Therefore, the four types of curves found in the study were classified into two groups: Desired type of lactation curves (standard and continuously increasing) and secondly, non-desired type of lactation curves (reverse standard and continuously decreasing). Table 2 and 3. The results show that for selection of Murrah buffalo on the consideration of desired type of curves, Wood model had shown a better fit with respect to monthly test-day milk yield in Murrah buffalo and could be used for prediction.
The exponential function (Wilmink model) with variable of constant (k) was also employed for modelling the average lactation curve parameters for various types of lactation shapes. When the results for different constants for Wilmink model were compared, it was noticed that in case of Wilmink model $(\mathrm{k}=0.05)$ had shown least good fitting of lactation curves, but the model becomes equally good for prediction when constant $\mathrm{k}$ in the model is increased to either 0.06 or 0.07 , indicating that constant $\mathrm{k}=0.05$ is not the appropriate constant to be used in Murrah buffaloes. Our results are in accordance with those described by Macciotta et al. (2005) fitted Wood function to test-day records of Italian Simmental cows and found that the Wood and Wilmink function could detect two main groups of curves i.e., standard and atypical/continuously decreasing curve besides reverse standard and continuously increasing types of lactation curve. The types of lactation curve obtained in our study were comparable to the ones obtained by Macciotta et al. 2005. The atypical curve was similar to our non-desired type of lactation curves. Vohra, 2010 reported desired and non-desired types of lactation curve for fortnightly test-day milk yield using Woods and Wilmink functions in Karan Fries cows wherein Woods function showed best fit. He reported that around 11 to 12 percent are non-desired type of animals and does not contribute to the farm yield. Jamuna (2015) fitted modified Wilmink function $(\mathrm{k}=0.07)$ to monthly test-day records in Murrah buffaloes. 


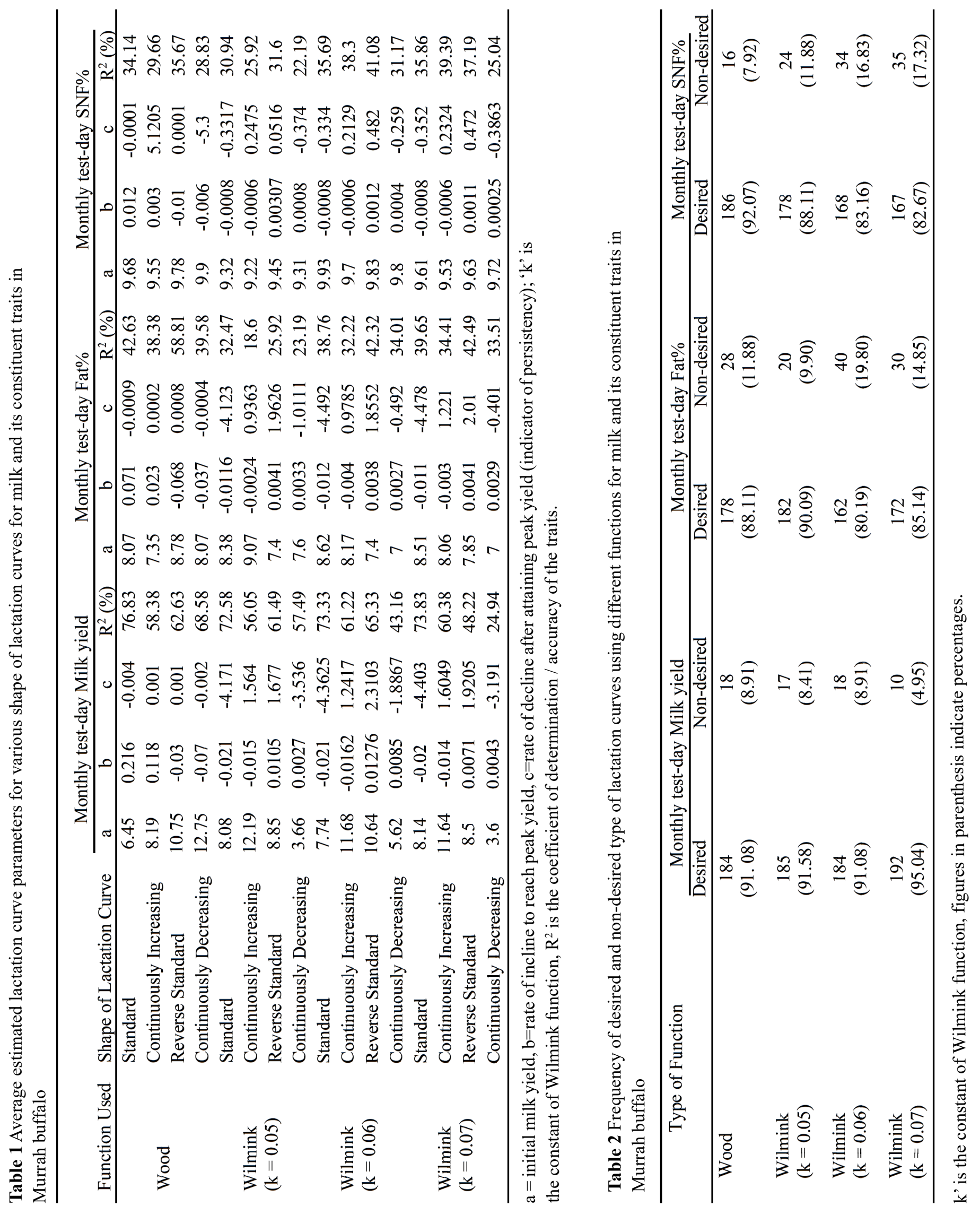




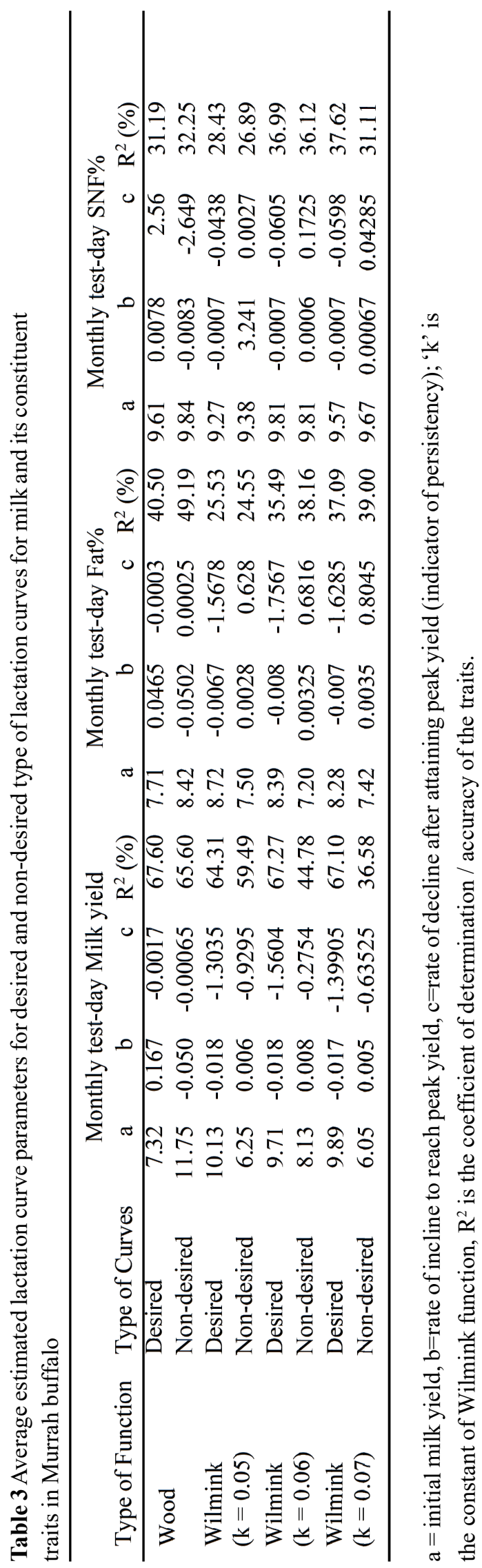

\section{Conclusions}

It could be inferred that Wood's incomplete gamma function fitted well to the monthly test-day milk, fat $\%$ and SNF\% yields of Murrah buffaloes as observed from the goodness of fit $\left(\mathrm{R}^{2}\right)$ for the function. Hence, Wood function can be effectively used for making breeding and management related decisions, particularly identifying the buffaloes with desired type of lactation curves for milk and milk constituent's traits. The exponential function when applied with constant $\mathrm{k}=0.06$ or 0.07 but not $\mathrm{k}=0.05$ can be used in prediction of milk and milk constituents with higher accuracy in Murrah buffaloes. Conventionally, in breeding programmes designed for selection of Murrah buffalo more emphasis is laid upon expected producing ability, which in turn depends on the genetic parameters and performance of the contemporaries. However, lactation curve shape and its parameter i.e. rate of decline after attaining peak lactation, could be used to select the high producing and persistent buffaloes.

\section{References}

Ali TE, Schaeffer LR (1987) Accounting for co-variances among test day milk yields in dairy cows. Can. J. Anim. Sci 67:637-644

Beever DE, Rook AJ, France J, Danhoa MS, Gill M (1991) A review of empirical and mechanistic models of lactational performance by the dairy cow. Livest Prod Sci 29:115-130

Grossman M, Koops WJ (1999) Modeling extended lactation curves of dairy cattle. A biological basis for the multiphasic approach. J Dairy Sci 86:988-998

Jamuna V (2015) Genetic and phenotypic profiling of lactation curve in Murrah buffaloes (Doctoral Thesis), National Dairy Research Institute, Karnal (Haryana).

Kellog DW, Urquhart S, Ortega AJ (1977) Estimating Holstein lactation curves with a gamma curve. J Dairy Sci 60:1308-1315

Kirkpatrick M, Lofsvold D, Bulmer M (1990) Analysis of the inheritance, selection and evolution of growth trajectories. Genetics 124:979993

Macciotta NPP, Vicario D, Cappio-Boriino A (2005) Detection of different shapes of lactation curve for milk yield in dairy cattle by empirical mathematical models. J Dairy Sci 88:1178-1191

Macciotta NPP, Dimauro C, Rassu SPG, Steri R, Pulina G (2011) The mathematical description of lactation curves in dairy cattle. Italian J Anim. Sci 10:e51

Sahoo SK, Singh A, Dash SK, Ambhore GS (2018) Modeling lactation curve for genetic evaluation of Murrah buffaloes. Indian J Anim Res 52:1675-1679

Strucken EM de Koning DJ, Rahmatalla SA, Brockmann GA (2011) Lactation curve models for estimating gene effects over a timeline J Dairy Sci 49: 442-449

Vohra V, Chakravarty AK, Chopra A (2011) Lactation curve modeling in KF cows using empirical mathematical model. J Anim Res1:57-61

Vohra V, Chopra A, Chakravarty AK (2017) Prediction of lactation persistency in crossbred cattle using genotype profile of lactation curve traits. Indian J Anim Sci 87:97-104

Vohra V, Chakravarty AK, Chopra A (2010) Revealing different shapes of lactation curves in Karan Fries cows. Indian J Dairy Sci 63:459-463

Wilmink JBM (1987) Adjustment of Test-Day milk, fat and protein yield for age, season and stage of lactation. Livest Prod Sci 16:335-348

Wood PDP (1967) Algebraic model of the lactation curve in cattle. Nature 216:164-166

$20^{\text {th }}$ Livestock Census (2019) All India Report. Department of Animal Husbandry, Dairying and Fisheries. Government of India. 